\title{
Self-reported work ability predicts health-related exit and absence from work, work participation, and death: longitudinal findings from a sample of German employees
}

\author{
Matthias Bethge $^{1}$ (D) Katja Spanier ${ }^{1}$ (D) . Stefanie Köhn ${ }^{2}$ (D) Anna Schlumbohm ${ }^{2}$ (D)
}

Received: 5 May 2020 / Accepted: 3 November 2020 / Published online: 21 November 2020

(C) The Author(s) 2020

\begin{abstract}
Objective The cohort study examined the performance of the Work Ability Index in predicting health-related exit and absence from work, work participation, and death among a sample of workers previously receiving sickness absence benefits.

Methods Workers aged 40-54 years who received sickness absence benefits in 2012 completed the Work Ability Index in 2013. Outcomes were extracted from administrative data records covering the period until the end of 2016.

Results Data for 2266 participants were included (mean age: 47.9 years; $54.4 \%$ women). Maximum follow-up was 43 months. In terms of work ability, $38.4 \%$ had good scores, $38.2 \%$ moderate scores, and $23.4 \%$ poor scores. Fully adjusted analyses showed an increased risk of a disability pension in workers with poor (HR=12.98; 95\% CI 5.81-28.99) and moderate Work Ability Index scores ( $\mathrm{HR}=3.17 ; 95 \%$ CI 1.36-7.38) compared to workers with good or excellent scores. The risk of a rehabilitation measure was also significantly increased for workers with poor and moderate scores. In addition, poor scores were prospectively associated with a longer duration of sickness absence and unemployment benefits, and fewer employment days and less income from regular employment. Those with poor Work Ability Index scores also had a significantly increased risk of premature death.

Conclusions The Work Ability Index is a potential tool to identify individuals with previous long-term sickness absence having an increased risk of health-related exit and absence from work and poor work participation outcomes.
\end{abstract}

Keywords Needs assessment · Occupational health $\cdot$ Rehabilitation $\cdot$ Pensions $\cdot$ Cohort study

\section{Introduction}

The prevention of work disability and maintenance of work ability may require different actions, ranging from simple workplace adjustments to multi-component programmes. Particularly in cases with complex needs, coordinated care is essential to harmonise endeavours and services. This usually requires additional financial and staff resources.

Electronic supplementary material The online version of this article (https://doi.org/10.1007/s00420-020-01608-4) contains supplementary material, which is available to authorized users.

Matthias Bethge

matthias.bethge@uksh.de

1 Institute for Social Medicine and Epidemiology, University of Lübeck, Ratzeburger Allee 160, 23562 Lübeck, Germany

2 Institute of Medical Sociology and Rehabilitation Science, Charité, Universitätsmedizin Berlin, Berlin, Germany
Risk-adjusted and stepped-care models are approaches that may achieve both efficient use of resources and access to coordinated care by establishing treatments of different levels of intensity. This model is well known from psychiatric care (Heddaeus et al. 2019) and has already been applied in occupational medicine and disability management (Aust et al. 2015; Poulsen et al. 2014; van Holland et al. 2012). In these models, the severity of symptoms or the prognosis determines the initial treatment choice. The patient's course is closely monitored. If the patient does not respond to treatment, care will continue at the next level of intensity.

One important precondition of risk-adjusted and steppedcare models is an assessment that can stratify people according to their risk of permanent work disability so that it is possible to select a risk-adjusted intervention. In many countries, like the Netherlands, the Scandinavian countries, and Germany, the identification of workers in need of coordinated care is mainly directed by the duration of sickness absence (Mittag et al. 2018). In Germany, the employer has 
to initiate reintegration management if a worker is unable to work for a period of more than 6 weeks due to the same illness. Though sickness absence is a good predictor of permanent work disability, only a small proportion of sick-listed workers really needs sustained support. There is a clear need of an assessment that is suitable to identify workers who probably need lasting and intensive support. For this purpose, several tools have been proposed (Amler et al. 2018; Escorpizo et al. 2009; Leggett et al. 2016a, b). One of them is the Work Ability Index (WAI), a short, self-report screening tool, which is currently available in about 30 languages (Ilmarinen 2007, 2009). The WAI was developed by Ilmarinen and colleagues at the Finnish Institute of Occupational Health (Ilmarinen 2019). The questionnaire assesses the degree to which workers consider their state of health adequate to cope with their job demands. The continuous scores can be categorised into groups that reflect different levels of need of support.

There is emerging evidence from longitudinal studies that the WAI predicts work disability as measured by healthrelated early retirement (Alavinia et al. 2009a; Bethge et al. 2013, 2018; Jääskeläinen et al. 2016; Roelen et al. 2014; Tuomi et al. 1991) and long-term sickness absence (Ahlstrom et al. 2010; Alavinia et al. 2009b; Bethge et al. 2012, 2018; Kujala et al. 2006; Lundin et al. 2017; Reeuwijk et al. 2015; Schouten et al. 2015, 2016). These findings come mainly from Scandinavian countries and the Netherlands. For Germany, this kind of evidence is not yet well established. We, therefore, set out to validate these findings within the German social security scheme using administrative data on health-related exit and absence from work (disability pension, rehabilitation, sickness absence benefits), work participation (unemployment benefits, days in and income from employment), and death. For this purpose, we recruited a large cohort of workers with prior episodes of receipt of sickness absence benefits. Focusing on employees who had previously received sickness absence benefits for an absence of more than 6 weeks due to illness should ensure that we could test whether the WAI is suitable for risk stratification of persons who should be accompanied by occupational health services as part of the in Germany legally required reintegration management. In a previous paper using the baseline data of our study, we showed that self-reported work ability measured by the WAI was associated with a higher prevalence of occupational and behavioural health risks (Bethge et al. 2015). In another paper, we reported that the WAI predicted disability pensions, use of rehabilitation services, sickness absence, and unemployment benefits, as well as income from and days in regular employment after a follow-up of roughly one and a half years (Bethge et al. 2018). For the following analysis, we were able to consider an extended follow-up of nearly 4 years. Moreover, in addition to previous analyses, we could also extract data on mortality from administrative records. This is of importance, as there is only one previous study that investigated the association between the WAI and mortality (von Bonsdorff et al. 2011). In summary, we assumed that the WAI is associated with health-related exit and absence from work, work participation, and death.

\section{Methods}

\section{Study design}

The Third German Sociomedical Panel of Employees (GSPE-III) is a cohort study that was established to investigate the determinants of work ability, rehabilitation use, and receipt of disability pensions among employees who had previously received sickness absence benefits, a group that is particularly vulnerable to health-related early retirement (www.gspe3.de/en/) (Bethge et al. 2015). We used the STROBE checklist when preparing the manuscript to ensure transparent and complete reporting of our study design and findings (Vandenbroucke et al. 2007).

\section{Setting and participants}

A sample of 10,000 people was drawn from the register of the Federal German Pension Insurance (GPI) (Bethge et al. 2015). This agency is part of the compulsory GPI scheme. In total, there are 16 agencies. The Federal GPI is the largest one and currently administers the pension contributions of around 23 million people (Deutsche Rentenversicherung Bund 2019). In the case of lasting work disability, the agencies have to pay a disability pension. Moreover, the pension insurance agencies can approve rehabilitation programmes for employees to improve and restore work ability and to avoid disability pensions. Sampling was restricted to those aged 40-54 years who had received sickness absence benefits in 2012. These benefits are usually paid in the case of sick leave episodes lasting more than 6 weeks. Those who had previously made pension requests were excluded, as were individuals who had requested or used rehabilitation services during the last 4 years. Men and women were sampled independently. The baseline questionnaires were sent in May 2013, and in the case of non-return, they were followed by one reminder 6 weeks later. If responders gave their approval, survey data were linked to administrative data records. Follow-up data from administrative records covering the years 2013-2016 were provided by the Federal GPI at the end of 2015 and 2017. These data came from the rehabilitation statistic data set that for a given year is available at the end of the following year. The study protocol was approved by the ethics committee of the Hannover Medical School (1730-2013) and the data protection commissioner 
of the Federal GPI. The GSPE-III was registered in the German Clinical Trials Register (DRKS00004824).

\section{Outcomes}

All outcome data were extracted from the administrative records of the Federal GPI. Administrative data were used to avoid recall bias and response bias due to selective sample attrition. Data on disability pensions, rehabilitation measures, and death covered the period from study entry in 2013 until the end of 2016. In addition to these events, we also considered the time at risk for these events in our analyses. Data on welfare benefits due to sickness absence and unemployment and data on employment were added for the years 2015 and 2016.

\section{Work Ability Index}

Work ability was assessed using the German version of the WAI questionnaire (Ilmarinen 2007). This self-report measure comprises seven scores, which are derived from 11 items: current work ability compared with lifetime best; work ability in relation to the physical and mental demands of the job (two items and an additional item to weigh physical and mental demands); number of current diseases diagnosed by a physician; estimated work impairment due to disease; sick leave during the past year; own prognosis of work ability 2 years from now; and mental resources (three items). The English version of the German questionnaire used in our study can be found elsewhere (Bethge et al. 2015). The total WAI score ranges from 7 to 49 points. Higher scores indicate better work ability. Levels of work ability can be categorised as poor (7-27 points), moderate (28-36 points), good (37-43 points), and excellent (44-49 points). We merged the upper categories to form one category of good scores due to the rather small number of outcome events in these categories. In line with Alavinia et al. (2009a) we distinguished among three levels of work ability when predicting our outcomes.

\section{Covariates}

Self-reported data and administrative data on demographics, work and work environment, health behaviour, and welfare benefits were considered as covariates. Age and sex were derived from administrative records. Self-reported demographic data comprised educational level (low, moderate, high) and partnership (partnered vs. single). Our categorisation of the educational level was based on the degrees that are possible in Germany. The German system distinguishes two lower secondary degrees which were categorised as low or moderate, and an upper secondary degree that enables access to tertiary education. Self-reported data on work and work environment covered volume of employment (full-time or part-time), job demands (mental work, physical work, an equal amount of mental and physical work) (Ilmarinen 2007), job position (blue collar vs. white collar) (Bethge et al. 2015), and size of enterprise ( $<50$ employees, 50-249 employees, $\geq 250$ employees) (European Commission 2015). Self-reported data on health behaviour included smoking (never smoker, current smoker, former smoker), sports ( $\geq 2 \mathrm{~h}$ per week vs. $<2 \mathrm{~h}$ per week), and obesity (body mass index $\geq 30$ vs. body mass index $<30$ ). The body mass index was calculated from self-reported height and weight. Welfare benefits due to sickness absence and unemployment, as well as days in employment and income from employment, were extracted from administrative records and covered the years 2011 and 2012.

\section{Study size}

The GSPE-III is a cohort study to explore a range of research questions related to the use of rehabilitation services and disability pensions. To enable us to follow up on rehabilitation use and disability pension for at least 3000 participants in the baseline survey, we drew a sample of 10,000 people. Assumptions regarding the response rate and the rate of consent to link survey and administrative data were derived from previous studies (Bethge and Radoschewski 2012; Bethge et al. 2012).

\section{Statistical analysis}

Descriptive statistics were used to characterise the full sample and samples stratified on the basis of levels of work ability. To describe the risk of disability pensions, rehabilitation, and death, we calculated absolute risks and rates per 1000 person-years. Time at risk was computed from the date of receipt of the questionnaire. Observations were censored at the end of 2016, and in case of disability pensions and rehabilitation also at the date of death. Kaplan-Meier curves were examined to compare the cumulative probability of disability pensions, rehabilitation, and death according to the level of work ability during the follow-up. Proportional hazard models were fitted to determine the supplementary prognostic benefit of the WAI when considering relevant covariates, and the hazard ratio (HR) and corresponding 95\% CI were estimated. We first calculated crude associations and then subsequently added age and sex, administrative data on welfare benefits and work participation in 2011 and 2012, and self-reported data from the baseline survey in 2013. To determine the associations between the WAI levels and sickness absence benefits and work participation outcomes in 2015 and 2016, linear regression models were fitted. All the covariates mentioned above were included in the final, fully adjusted models. 
Missing self-reported baseline data were imputed using chained equations (Royston and White 2011). Parameters without missing values (age, sex, job demands, and administrative data) were included as covariates in the imputation model. We created 20 independent data sets with complete values. Parameter estimates of the proportional hazard and the linear regression models were combined in accordance with Rubin's rules (Little and Rubin 2002).

The statistical test results were regarded as significant if the two-sided $p$ value of a test was less than 0.05. All calculations were performed in Stata SE 15.

\section{Results}

\section{Recruitment and participants}

Of the 10,000 questionnaires sent, 103 could not be delivered. Completed questionnaires were returned by 3294 $(33.3 \%)$ individuals. The responders were marginally older than non-responders (47.9 vs. 47.2 years) and slightly more likely to be female (53.6\% vs. $48.4 \%)$. We excluded 305 participants due to their unemployment by the time of the initial survey, six participants due to missing information concerning their employment status, and 170 participants due to missing data for self-reported work ability. Of the remaining 2813 people, 2342 (83.3\%) participants agreed to the linking of questionnaire data and administrative data records, whereas 471 participants refused. Sixty-seven persons were excluded because they changed their pension agency, and data about them was no longer available from the Federal GPI. Nine subjects were excluded because they applied for a disability pension benefit before the baseline questionnaire was registered by the research team. In total, 2266 participants were eligible for analysis related to disability pensions, rehabilitation, and death. In the case of the data on sickness absence and unemployment benefits, and employment data, 146 additional subjects had to be excluded due to incomplete administrative data records. Online Resource 1 shows the flow of participants.

Table 1 presents selected baseline characteristics and outcomes of the total sample and stratified for self-reported work ability. The mean age was 47.9 years, and $54.4 \%$ were women. In terms of work ability, $38.4 \%$ had good scores, $38.2 \%$ moderate scores, and $23.4 \%$ poor scores. The complete table of all baseline characteristics is available as Online Resource 2.

\section{Disability pensions, rehabilitation, and death}

During the maximum follow-up of 43 months (3.6 years), 94 participants $(4.1 \%)$ were approved a disability pension, $471(20.8 \%)$ were approved a rehabilitation measure, and
$29(1.3 \%)$ died. The absolute risks of receiving a disability pension were $11.7,2.9$, and $0.8 \%$ for those with poor, moderate, and good work ability, respectively. The risks of a rehabilitation event were $36.7,20.9$, and $10.9 \%$; the risks of death were $2.6,1.4$, and $0.3 \%$. Table 2 reports the incidence rates per 1000 person-years, and Fig. 1 shows the cumulative probability of approved disability pensions, rehabilitation, and death.

The adjusted risk estimates from the proportional hazard models are presented in Table 3 . The results show that the associations between baseline work ability and disability pensions, rehabilitation, and death were only slightly reduced when adjusting for age and sex, baseline data from the administrative records, and self-reported data. In the final, fully adjusted model, poor work ability was associated with an approximately 13 times greater risk $(\mathrm{HR}=12.98$; 95\% CI 5.81-28.99) of a disability pension during follow-up than good work ability. Moderate work ability was associated with a risk that was about 3 times as great $(\mathrm{HR}=3.17$; 95\% CI 1.36-7.38). The risk of a rehabilitation event during follow-up was 4 times greater for workers with poor work ability (HR $=3.90 ; 95 \%$ CI 3.02-5.05) and twice for workers with moderate work ability (HR $=1.91 ; 95 \%$ CI $1.48-2.46)$. Moreover, poor work ability was associated with a risk of death 6 times greater $(\mathrm{HR}=6.19 ; 95 \% \mathrm{CI} 1.70-22.53)$, while the risk for persons with moderate work ability did not significantly increase.

\section{Sickness absence benefits and work participation}

Table 4 shows the adjusted estimates of the prognostic relevance of the work ability categories for sickness absence benefits and work participation outcomes in 2015 and 2016. Compared to participants with good work ability, those with poor work ability had 32 additional days of sickness absence benefits and 32 additional days of unemployment benefits. Moreover, days in employment were reduced by 151 days among participants with poor work ability; the 2 -year income was reduced by 16,566 euros. Participants with moderate work ability had 11 additional days of sickness absence benefits when compared to those with good work ability, while days in employment were decreased by 39 days and the 2 -year income was 3548 euros less.

\section{Discussion}

Participants with poor and moderate WAI scores had an elevated risk of permanent work disability and premature death, longer periods of sickness absence benefits, and shorter periods of employment and less income from employment even after adjusting for a range of other variables. Poor WAI scores were also associated with an 


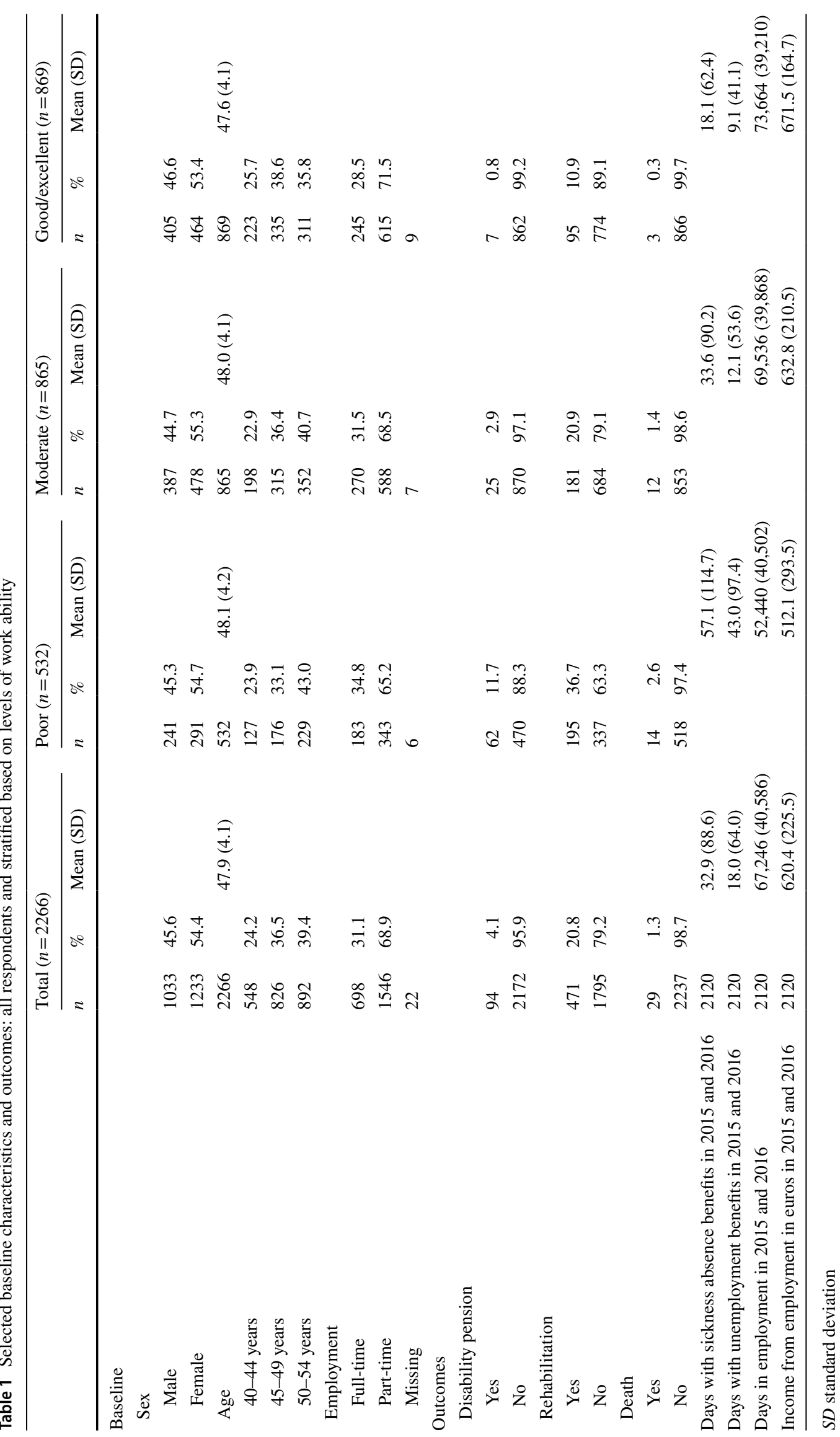


Table 2 Incidence rate per 1000 person-years of disability pensions, rehabilitation, and death: all respondents and stratified based on levels of self-reported work ability

\begin{tabular}{|c|c|c|c|c|c|c|c|c|}
\hline & \multicolumn{2}{|c|}{ Total $(n=2266)$} & \multicolumn{2}{|c|}{ Poor $(n=532)$} & \multicolumn{2}{|c|}{ Moderate $(n=865)$} & \multicolumn{2}{|c|}{$\begin{array}{l}\text { Good/excellent } \\
(n=869)\end{array}$} \\
\hline & IR & $95 \% \mathrm{CI}$ & IR & $95 \% \mathrm{CI}$ & IR & $95 \% \mathrm{CI}$ & IR & $95 \% \mathrm{CI}$ \\
\hline Disability pension & 12.35 & $10.09 ; 15.11$ & 36.75 & $28.65 ; 47.14$ & 8.49 & $5.74 ; 12.57$ & 2.35 & $1.12 ; 4.92$ \\
\hline Rehabilitation & 68.85 & $62.90 ; 75.36$ & 143.74 & $124.92 ; 165.40$ & 68.84 & $59.51 ; 79.64$ & 33.27 & $27.21 ; 40.68$ \\
\hline Death & 3.74 & $2.60 ; 5.38$ & 7.86 & $4.65 ; 13.27$ & 4.03 & $2.29 ; 7.09$ & 1.00 & $0.32 ; 3.11$ \\
\hline
\end{tabular}

$n=2266 ; I R$ incidence rate per 1000 person-years; $C I$ confidence interval
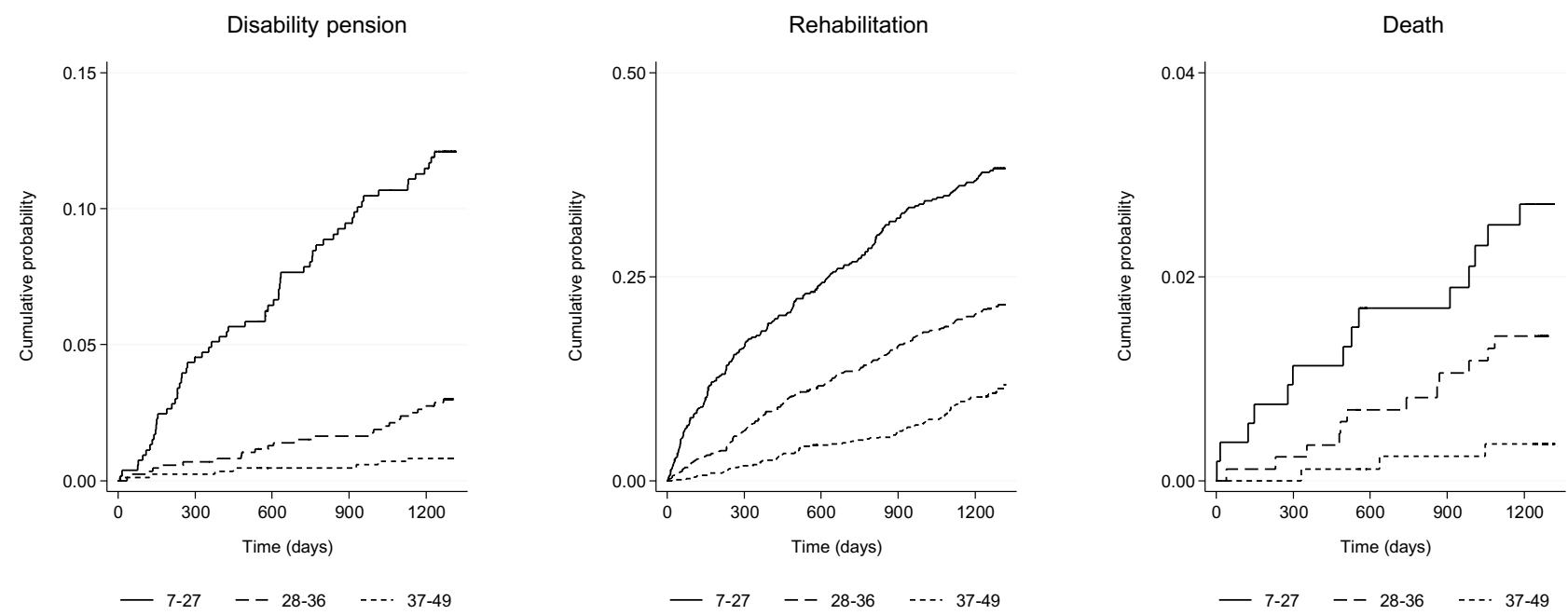

Fig. 1 Cumulative probability of disability pension, rehabilitation, and death based on levels of self-reported work ability during the follow-up. $n=2266$

Table 3 Association between self-reported work ability and disability pension, rehabilitation, and death in the period 2013-2016: hazard ratios and $95 \%$ confidence intervals

\begin{tabular}{|c|c|c|c|c|c|c|c|c|c|}
\hline & \multicolumn{3}{|c|}{ Disability pension } & \multicolumn{3}{|c|}{ Rehabilitation } & \multicolumn{3}{|c|}{ Death } \\
\hline & HR & $95 \% \mathrm{CI}$ & $p$ & HR & $95 \% \mathrm{CI}$ & $p$ & HR & $95 \% \mathrm{CI}$ & $p$ \\
\hline \multicolumn{10}{|l|}{ Crude } \\
\hline Poor & 15.57 & $7.13 ; 34.02$ & $<0.001$ & 7.80 & $2.24 ; 27.15$ & 0.001 & 4.25 & $3.33 ; 5.44$ & $<0.001$ \\
\hline Moderate & 3.61 & $1.56 ; 8.36$ & 0.003 & 4.02 & $1.13 ; 14.24$ & 0.031 & 2.06 & $1.61 ; 2.64$ & $<0.001$ \\
\hline \multicolumn{10}{|c|}{ Adjusted for age and sex } \\
\hline Poor & 15.12 & $6.92 ; 33.06$ & $<0.001$ & 7.65 & $2.20 ; 26.65$ & 0.001 & 4.17 & $3.26 ; 5.33$ & $<0.001$ \\
\hline Moderate & 3.49 & $1.51 ; 8.07$ & 0.004 & 3.98 & $1.12 ; 14.11$ & 0.033 & 2.01 & $1.57 ; 2.57$ & $<0.001$ \\
\hline \multicolumn{10}{|c|}{ Additionally adjusted for administrative data } \\
\hline Poor & 13.09 & $5.92 ; 28.94$ & $<0.001$ & 6.26 & $1.76 ; 22.35$ & 0.005 & 4.04 & $3.14 ; 5.20$ & $<0.001$ \\
\hline Moderate & 3.29 & $1.42 ; 7.63$ & 0.005 & 3.67 & $1.03 ; 13.10$ & 0.045 & 1.98 & $1.54 ; 2.54$ & $<0.001$ \\
\hline \multicolumn{10}{|c|}{ Additionally adjusted for self-reported data } \\
\hline Poor & 12.98 & $5.81 ; 28.99$ & $<0.001$ & 6.19 & $1.70 ; 22.53$ & 0.006 & 3.90 & $3.02 ; 5.05$ & $<0.001$ \\
\hline Moderate & 3.17 & $1.36 ; 7.38$ & 0.007 & 3.55 & $0.99 ; 12.78$ & 0.053 & 1.91 & $1.48 ; 2.46$ & $<0.001$ \\
\hline
\end{tabular}

$n=2266 ; H R$ hazard ratio, $C I$ confidence interval; estimates from the final, fully adjusted were calculated using imputed data from 20 imputed data sets 
Table 4 Association between self-reported work ability and sickness absence benefits and work participation outcomes in 2015 and 2016 : adjusted mean differences and $95 \%$ confidence intervals

\begin{tabular}{|c|c|c|c|c|}
\hline & \multicolumn{2}{|c|}{ Poor vs. good work ability } & \multicolumn{2}{|c|}{ Moderate vs. good work ability } \\
\hline & $b$ & $95 \% \mathrm{CI}$ & $b$ & $95 \% \mathrm{CI}$ \\
\hline Days with sickness absence benefits in 2015 and 2016 & 32.3 & $22.0 ; 42.6$ & 11.3 & $2.7 ; 19.9$ \\
\hline Days with unemployment benefits in 2015 and 2016 & 31.8 & $24.4 ; 39.1$ & 2.5 & $-3.6 ; 8.7$ \\
\hline Days in employment in 2015 and 2016 & -151.0 & $-175.1 ;-126.8$ & -39.4 & $-59.7 ;-19.2$ \\
\hline Income from employment in 2015 and 2016 & $-16,566$ & $-19,465 ;-13,666$ & -3548 & $-5974 ;-1123$ \\
\hline
\end{tabular}

$n=2120 ; b$ unstandardised estimate, $C I$ confidence interval; estimates are adjusted for age, sex, education, partnership, employment, job demands, job position, size of enterprise, smoking, body mass index, sports activity, days with sickness absence benefits (2011 and 2012), days with unemployment benefits (2011 and 2012), days in employment (2011 and 2012), and income from employment in euros (2011 and 2012). Estimates of the final, fully adjusted model were calculated using imputed data from 20 imputed data sets

increased likelihood of using rehabilitation services and longer periods of receiving unemployment benefits.

Our findings are consistent with the emerging evidence from large high-quality cohort studies, which started in Scandinavian countries and the Netherlands in the 1980s to clarify if the WAI is able to identify workers with an increased risk of permanent work disability. Jääskeläinen et al. (2016) recently reported that the WAI predicted disability pensions in a cohort of 5251 Finnish municipal employees. The adjusted HRs were quite similar to our estimates. Roelen et al. (2014) used the continuous WAI score to predict disability pensions in 9350 Dutch workers and found that the continuous score discriminated well between workers with and without future disability pensions. Schouten et al. in two publications and Reeuwijk et al. showed reasonable performance of the WAI in predicting sickness absence spells of different durations drawing on large Dutch samples of more than 1000 people (Reeuwijk et al. 2015; Schouten et al. 2015, 2016). Additionally, there is strong evidence from two large Swedish cohort studies that the WAI and its single items are associated with an increased risk of a disability pension (Lundin et al. 2016, 2017). Moreover, poor work ability as measured with the first item of the WAI may impact beyond retirement. Bonsdorff et al. (2011) showed with 28-year follow-up data from the Finnish Longitudinal Study of Municipal Employees that poor work abilityas in our study - was associated with mortality, and that poor work ability nearly doubled the risk of some form of disability when performing activities of daily living as senior citizens.

Efficient use of resources when managing occupational health services can be supported by providing a risk-adjusted selection of pathways instead of relying on one-size-fits-all measures. This assures that unnecessary efforts in individuals with a low risk are abandoned while individuals with a high risk receive the intense support that they need. Our findings indicate that the WAI is a prognostic relevant tool to identify who is at risk and who needs intense and coordinated care.

A critical appraisal of the findings of this study has to consider the following limitations. First, the response rate of only approximately one-third reflects a risk of bias, although a comparison of responders and non-responders showed only minor differences related to age and sex. Second, the analyses were restricted to participants who approved the linking of questionnaire data and administrative data records. This further limited the sample, as only $83.3 \%$ agreed to this data linkage. Third, the workers in our sample were predominantly employed in the public sector. This was the result of sampling participants from the register of the Federal GPI. Workers who are part of this pension scheme are characterised by higher educational levels, higher vocational qualifications, and higher income, and they are less frequently exposed to high physical demands in the workplace compared to the general population. Fourth, we used the categorized WAI total score in our analyses, only. We showed that the categorized WAI total score is a robust prognostic measure considering a range of work participation outcomes. However, depending on the outcome, the single dimensions of the WAI may have a similar prognostic value as the total score. Additional analyses are needed to clarify, for which outcomes single dimensions of the WAI may be sufficient to predict work participation outcomes, and to what amount the prognostic value is driven by the seven single dimensions (Reeuwijk et al. 2015). Finally, several models to predict work disability were published in recent years. While these models were useful to identify risk factors, they were mostly not good enough to validly determine who is likely to leave the workforce. Burdorf (2019) suggested that occupational health care professional should focus their efforts on reducing well-established and widespread risk factors, rather than developing even more sophisticated predictive models to identify high-risk individuals as accurately as possible.

These limitations are balanced by several strengths. First, the sample was drawn from the register of the 
country's largest pension body, the Federal GPI, and was restricted to those who had previously received sickness benefits (i.e., a group particularly at risk of early retirement and permanent work disability, and, therefore, in need of effective occupational health care). The distribution of the WAI categories, therefore, differed clearly from other studies using the WAI to predict work participation outcomes, and people with poor and moderate WAI scores were overrepresented (Jääskeläinen et al. 2016; Reeuwijk et al. 2015; Roelen et al. 2014). Second, the linking of the questionnaire data and administrative data records allowed follow-up without sample attrition. Third, the use of administrative data allowed complete, valid, and reliable assessment of our study outcomes. Thus, recall bias and misclassification were avoided. Fourth, our extended follow-up was nearly 4 years, and the median time to claim a disability pension in case of an event was roughly 19 months. We are confident that this time span would enable to offer complex multi-component programmes to prevent disability pensions.

In conclusion, the WAI groups workers into categories with different risks of permanent work disability and may be used to organise risk-adjusted and stepped-care models in occupational health care settings.

Author contributions MB planned and designed the study. Material preparation, data collection and analysis were performed by MB, KS, SK, and AS. The first draft of the manuscript was written by MB, and all authors commented on previous versions of the manuscript. All authors read and approved the final manuscript.

Funding Open Access funding enabled and organized by Projekt DEAL. This research was funded by the Federal German Pension Insurance Insurance, and this institution paid money to the University of Lübeck and the Charité-Universitätsmedizin Berlin.

Data availability All data relevant to the study are included in the article or uploaded as supplementary information.

Code availability The code generated to analyse the data is available from the corresponding author on reasonable request.

\section{Compliance with ethical standards}

Conflict of interests The authors received grants from the Federal German Pension Insurance during the conduct of the study.

Ethical approval All procedures performed in the studies involving human participants were in accordance with the ethical standards of the institutional and/or national research committee, and with the 1964 Helsinki Declaration and its later amendments or comparable ethical standards. The study protocol was approved by the ethics committee of the Hannover Medical School (1730-2013) and the data protection commissioner of the Federal GPI.

Consent to participate Informed consent was obtained from all participants included in the study.
Open Access This article is licensed under a Creative Commons Attribution 4.0 International License, which permits use, sharing, adaptation, distribution and reproduction in any medium or format, as long as you give appropriate credit to the original author(s) and the source, provide a link to the Creative Commons licence, and indicate if changes were made. The images or other third party material in this article are included in the article's Creative Commons licence, unless indicated otherwise in a credit line to the material. If material is not included in the article's Creative Commons licence and your intended use is not permitted by statutory regulation or exceeds the permitted use, you will need to obtain permission directly from the copyright holder. To view a copy of this licence, visit http://creativecommons.org/licenses/by/4.0/.

\section{References}

Ahlstrom L, Grimby-Ekman A, Hagberg M, Dellve L (2010) The work ability index and single-item question: associations with sick leave, symptoms, and health-a prospective study of women on long-term sick leave. Scand J Work Environ Health $36: 404-412$

Alavinia SM, de Boer AG, van Duivenbooden JC, Frings-Dresen MH, Burdorf A (2009) Determinants of work ability and its predictive value for disability. Occup Med (Lond) 59:32-37

Alavinia SM, van den Berg TI, van Duivenbooden C, Elders LA, Burdorf A (2009) Impact of work-related factors, lifestyle, and work ability on sickness absence among Dutch construction workers. Scand J Work Environ Health 35:325-333

Amler N, Felder S, Mau W, Merkesdal S, Schoffski O (2018) Instruments for measuring the effects of early intervention on maintaining and restoring ability to work in Germany: opinion of an interdisciplinary working group. Gesundheitswesen 80:79-86

Aust B et al (2015) Implementation of the Danish return-to-work program: process evaluation of a trial in 21 Danish municipalities. Scand J Work Environ Health 41:529-541

Bethge M, Radoschewski FM (2012) Adverse effects of effort-reward imbalance on work ability: longitudinal findings from the German Sociomedical Panel of Employees. Int J Public Health 57:797-805

Bethge M, Radoschewski FM, Gutenbrunner C (2012) The Work Ability Index as a screening tool to identify the need for rehabilitation: longitudinal findings from the Second German Sociomedical Panel of Employees. J Rehabil Med 44:980-987

Bethge M, Gutenbrunner C, Neuderth S (2013) Work Ability Index predicts application for disability pension after work-related medical rehabilitation for chronic back pain. Arch Phys Med Rehabil 94:2262-2268

Bethge M, Spanier K, Neugebauer T, Mohnberg I, Radoschewski FM (2015) Self-reported poor work ability-an indicator of need for rehabilitation? A cross-sectional study of a sample of German employees. Am J Phys Med Rehabil 94:958-966

Bethge M, Spanier K, Peters E, Michel E, Radoschewski M (2018) Self-reported work ability predicts rehabilitation measures, disability pensions, other welfare benefits, and work participation: longitudinal findings from a sample of German employees. J Occup Rehabil 28:495-503

Burdorf A (2019) Prevention strategies for sickness absence: sick individuals or sick populations? Scand J Work Environ Health 45:101-102

European Commission (2015) User guide to the SME definition. Publications Office of the European Union, Luxembourg

Deutsche Rentenversicherung Bund (2019) Insured persons 2017. Deutsche Rentenversicherung Bund, Berlin

Escorpizo R, Cieza A, Beaton D, Boonen A (2009) Content comparison of worker productivity questionnaires in arthritis and musculoskeletal conditions using the International Classification of 
Functioning, Disability, and Health framework. J Occup Rehabil 19:382-397

Heddaeus D et al (2019) Study protocol for the COMET study: a cluster-randomised, prospective, parallel-group, superiority trial to compare the effectiveness of a collaborative and stepped care model versus treatment as usual in patients with mental disorders in primary care. BMJ Open 9:e032408

Ilmarinen J (2007) The work ability index (WAI). Occup Med (Lond) $57: 160$

Ilmarinen J (2009) Work ability-a comprehensive concept for occupational health research and prevention. Scand J Work Environ Health 35:1-5

Ilmarinen J (2019) From work ability research to implementation. Int J Environ Res Public Health 16:2882

Jääskeläinen A, Kausto J, Seitsamo J, Ojajärvi A, Nygard CH, Arjas E, Leino-Arjas P (2016) Work ability index and perceived work ability as predictors of disability pension: a prospective study among Finnish municipal employees. Scand J Work Environ Health 42:490-499

Kujala V, Tammelin T, Remes J, Vammavaara E, Ek E, Laitinen J (2006) Work ability index of young employees and their sickness absence during the following year. Scand J Work Environ Health $32: 75-84$

Leggett $\mathrm{S}$ et al (2016a) Content validity of global measures for at-work productivity in patients with rheumatic diseases: an international qualitative study. Rheumatology (Oxford) 55:1364-1373

Leggett $\mathrm{S}$ et al (2016b) Test-retest reliability and correlations of 5 global measures addressing at-work productivity loss in patients with rheumatic diseases. J Rheumatol 43:433-439

Little R, Rubin D (2002) Statistical analysis with missing data. Wiley, Hoboken

Lundin A, Kjellberg K, Leijon O, Punnett L, Hemmingsson T (2016) The association between self-assessed future work ability and long-term sickness absence, disability pension and unemployment in a general working population: a 7-year follow-up study. $\mathrm{J}$ Occup Rehabil 26:195-203

Lundin A, Leijon O, Vaez M, Hallgren M, Torgen M (2017) Predictive validity of the Work Ability Index and its individual items in the general population. Scand J Public Health 45:350-356

Mittag O, Kotkas T, Reese C, Kampling H, Groskreutz H, de Boer W, Welti F (2018) Intervention policies and social security in case of reduced working capacity in the Netherlands, Finland and Germany: a comparative analysis. Int J Public Health 63:1081-1088
Poulsen OM et al (2014) Effect of the Danish return-to-work program on long-term sickness absence: results from a randomized controlled trial in three municipalities. Scand J Work Environ Health 40:47-56

Reeuwijk KG, Robroek SJ, Niessen MA, Kraaijenhagen RA, Vergouwe Y, Burdorf A (2015) The prognostic value of the Work Ability Index for sickness absence among office workers. PLoS ONE 10:e0126969

Roelen CA, Heymans MW, Twisk JW, van der Klink JJ, Groothoff JW, van Rhenen W (2014) Work Ability Index as tool to identify workers at risk of premature work exit. J Occup Rehabil 24:747-754

Royston P, White I (2011) Multiple imputation by chained equations (MICE): implementation in Stata. J Stat Software 45:2-20

Schouten LS, Joling CI, van der Gulden JW, Heymans MW, Bultmann U, Roelen CA (2015) Screening manual and office workers for risk of long-term sickness absence: cut-off points for the Work Ability Index. Scand J Work Environ Health 41:36-42

Schouten LS, Bultmann U, Heymans MW, Joling CI, Twisk JW, Roelen CA (2016) Shortened version of the work ability index to identify workers at risk of long-term sickness absence. Eur J Public Health 26:301-305

Tuomi K, Toikkanen J, Eskelinen L, Backman AL, Ilmarinen J, Jarvinen E, Klockars M (1991) Mortality, disability and changes in occupation among aging municipal employees. Scand J Work Environ Health 17(Suppl 1):58-66

van Holland BJ, de Boer MR, Brouwer S, Soer R, Reneman MF (2012) Sustained employability of workers in a production environment: design of a stepped wedge trial to evaluate effectiveness and costbenefit of the POSE program. BMC Public Health 12:1003

Vandenbroucke JP et al (2007) Strengthening the Reporting of Observational Studies in Epidemiology (STROBE): explanation and elaboration. Epidemiology 18:805-835

von Bonsdorff MB, Seitsamo J, Ilmarinen J, Nygard CH, von Bonsdorff ME, Rantanen T (2011) Work ability in midlife as a predictor of mortality and disability in later life: a 28 -year prospective followup study. CMAJ 183:E235-242

Publisher's Note Springer Nature remains neutral with regard to jurisdictional claims in published maps and institutional affiliations. 